\title{
A compact multifunctional microfluidic platform for exploring cellular dynamics in real- time using electrochemical detection
}

Zor, Kinga; Heiskanen, Arto; Caviglia, Claudia; Vergani, M.; Landini, E.; Shah, Fozia; Carminati, M.; Martínez-Serrano, A.; Moreno, T. Ramos ; Kokaia, M.

Total number of authors:

21

Published in:

R S C Advances

Link to article, DOI:

$10.1039 / \mathrm{c} 4 \mathrm{ra} 12632 \mathrm{~g}$

Publication date:

2014

Document Version

Publisher's PDF, also known as Version of record

Link back to DTU Orbit

Citation (APA):

Zor, K., Heiskanen, A., Caviglia, C., Vergani, M., Landini, E., Shah, F., Carminati, M., Martínez-Serrano, A., Moreno, T. R., Kokaia, M., Benayahu, D., Keresztes, Z., Papkovsky, D., Wollenberger, U., Svendsen, W. Ë., Dimaki, M., Ferrari, G., Raiteri, R., Sampietro, M., ... Emnéus, J. (2014). A compact multifunctional microfluidic platform for exploring cellular dynamics in real-time using electrochemical detection. R S C Advances, 4, 63761-63771. https://doi.org/10.1039/c4ra12632g

\section{General rights}

Copyright and moral rights for the publications made accessible in the public portal are retained by the authors and/or other copyright owners and it is a condition of accessing publications that users recognise and abide by the legal requirements associated with these rights.

- Users may download and print one copy of any publication from the public portal for the purpose of private study or research.

- You may not further distribute the material or use it for any profit-making activity or commercial gain

- You may freely distribute the URL identifying the publication in the public portal 


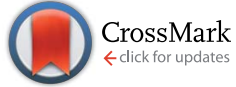

Cite this: RSC Adv., 2014, 4, 63761

Received 17th October 2014

Accepted 13th November 2014

DOI: $10.1039 / \mathrm{c} 4 \mathrm{ra12632 \textrm {g }}$

www.rsc.org/advances

\section{A compact multifunctional microfluidic platform for exploring cellular dynamics in real-time using electrochemical detection}

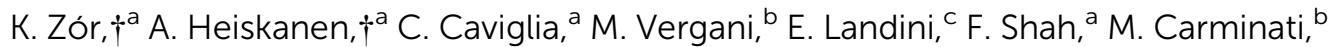
A. Martínez-Serrano, ${ }^{d}$ T. Ramos Moreno, de M. Kokaia, ${ }^{e}$ D. Benayahu, ${ }^{f}$ Zs. Keresztes, ${ }^{g}$ D. Papkovsky, ${ }^{\text {h }}$ U. Wollenberger, ${ }^{i}$ W. E. Svendsen, ${ }^{a}$ M. Dimaki, ${ }^{a}$ G. Ferrari, ${ }^{b}$ R. Raiteri, ${ }^{c}$ M. Sampietro, ${ }^{\text {b } M . ~ D u f v a ~}{ }^{a}$ and J. Emnéus ${ }^{* a}$

Downscaling of microfluidic cell culture and detection devices for electrochemical monitoring has mostly focused on miniaturization of the microfluidic chips which are often designed for specific applications and therefore lack functional flexibility. We present a compact microfluidic cell culture and electrochemical analysis platform with in-built fluid handling and detection, enabling complete cell based assays comprising on-line electrode cleaning, sterilization, surface functionalization, cell seeding, cultivation and electrochemical real-time monitoring of cellular dynamics. To demonstrate the versatility and multifunctionality of the platform, we explored amperometric monitoring of intracellular redox activity in yeast (Saccharomyces cerevisiae) and detection of exocytotically released dopamine from rat pheochromocytoma cells (PC12). Electrochemical impedance spectroscopy was used in both applications for monitoring cell sedimentation and adhesion as well as proliferation in the case of PC12 cells. The influence of flow rate on the signal amplitude in the detection of redox metabolism as well as the effect of mechanical stimulation on dopamine release were demonstrated using the programmable fluid handling capability. The here presented platform is aimed at applications utilizing cell based assays, ranging from e.g. monitoring of drug effects in pharmacological studies, characterization of neural stem cell differentiation, and screening of genetically modified microorganisms to environmental monitoring.

\section{Introduction}

When designing a microfluidic device for cell-based analysis, specific requirements for a biological problem need to be carefully taken into consideration. This leads to construction of tailor-made devices to primarily address one biological

${ }^{a}$ Department of Micro- and Nanotechnology, Technical University of Denmark, Produktionstorvet 423, DK-2800 Kgs. Lyngby, Denmark. E-mail: Jenny.Emneus@ nanotech.dtu.dk; Tel: $+45-45256867$

${ }^{b}$ Dipartimento di Elettronica, Informazione e Bioingegneria, Politecnico di Milano, Milan, Italy

'Department of Informatics, Bioengineering, Robotics, and System Engineering, University of Genova, Genova, Italy

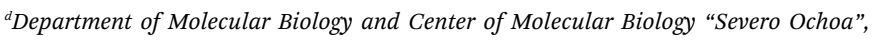
University Autónoma de Madrid, Madrid, Spain

${ }^{e}$ Wallenberg Neuroscience Center, Lund University, Lund, Sweden

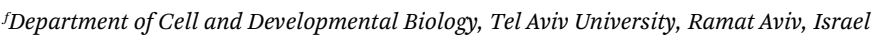
${ }^{g}$ Research Center for Natural Sciences, Hungarian Academy of Sciences, Budapest, Hungary

${ }^{h}$ Department of Biochemistry and Cell Biology, University College Cork, Cork, Ireland ${ }^{i}$ Department of Molecular Enzymology, University of Potsdam, Potsdam (Golm), Germany

$\dagger$ These authors contributed equally to this study. function; operational flexibility and multifunctionality of the devices is rarely realized. ${ }^{1}$ Moreover, since the main focus is on development of specialized microfluidic cell culture chips, miniaturization of 'in-built' liquid handling and detection units is often overlooked; ${ }^{2}$ hence, bulky off-chip instrumentation is still required for fluidic operations and detection.

Monitoring of cellular dynamic processes (e.g. detection of messenger molecules, neurotransmitters, intracellular redox changes) can provide valuable information about cellular functions and evolution of various diseases, opening up possibilities for their treatment. Imbalance in production and release of neurotransmitters as well as intracellular redox metabolism have important implications for development and evolution of neurodegenerative disorders..$^{3-5}$ Only for the treatment of these pathological conditions, almost 700 drugs are under development. ${ }^{6}$ Although well-established cell based in vitro assays have a significant role in drug discovery ${ }^{7}$ and toxicity assessement, ${ }^{8}$ there is a need for tools enabling cellular investigations on microscale allowing low sample consumption combined with fast and high-content analysis. Combination of in vitro cell based assays with in situ real-time monitoring, while keeping the cells intact, can provide a powerful analysis tool for cell based assays. 
In comparison with static cell cultures, microfluidic cell culture devices can provide a more stable environment during long-term cell culturing, eliminating fluctuations in medium content and removal of metabolic waste products, as well as providing continuous nutrient and oxygen supply while minimizing risk for contamination. ${ }^{9}$ Microfluidic cell culture devices have been used in studies on drug metabolism and toxicity, ${ }^{\mathbf{1 0}}$ as a diagnostic tool for neurological disorder, ${ }^{\mathbf{1 1}}$ and for evaluating the influence of different factors on cancer development and stem cell differentiation..$^{12,13}$

Electrochemical detection techniques, on the other hand, enable real-time measurements without destroying cellular integrity ${ }^{\mathbf{1 4 5}}$ and can be miniaturized, multiplexed, and automated without losing their performance. ${ }^{16,17}$ Moreover, they can easily be integrated with microfluidics ${ }^{17,18}$ and have therefore been applied for a range of biological applications, e.g., detection of cancer markers, ${ }^{19}$ drug screening, ${ }^{20}$ monitoring of enzyme kinetics, ${ }^{21}$ drug metabolism studies, ${ }^{22}$ as well as for detection of biologically important molecules such as nitric oxide and peroxynitrite. ${ }^{23}$

Here, we present the design and development of a compact multifunctional microfluidic platform for monitoring of cellular dynamics, from here on referred to as EXCELL platform (EXploring CELLular Dynamics at Nanoscale) as the outcome of EU funded project, facilitating both cell culturing and electrochemical real-time cell analysis combined with microscopic observations while maintaining cellular integrity. The platform comprises all the necessary units for fluidic operations and electrochemical detection: (i) microfluidic motherboard with integrated programmable peristaltic micropumps, ${ }^{24}$ as well as reagent- and waste reservoirs, (ii) exchangeable microfluidic cell culture and analysis chip with an integrated 12-microelectrode array chip, ${ }^{25,26}$ and (iii) a miniaturized tailor-made 12-channel bipotentiostat realized on a printed circuit board operated by a tailor-made acquisition and analysis software ${ }^{27}$ that also enables control of the micropumps. The multifunctionality of the EXCELL platform is characterized by its ability to facilitate different cell based assays. As examples, two established cell based assays, (i) amperometric monitoring of intracellular redox activity in yeast (Saccharomyces cerevisiae) and (ii) detection of the exocytotically released dopamine (DA) from rat pheochromocytoma cells (PC12), were performed following changes in cellular dynamics.

The intracellular redox metabolism in yeast (Saccharomyces cerevisiae) has been monitored amperometrically under static conditions in immobilized cells using soluble double mediator system menadione/potassium hexacyanoferrate III (ferricyanide), ${ }^{28}$ and the applicability of the assay in a microfluidic environment was preliminarily evaluated. ${ }^{29}$ Recently, intracellular redox activity of yeast cells was achieved by 'wiring' the cells to the electrode surface with a polymeric mediator (redox active osmium polymer) applied in a microfluidic environment. ${ }^{30}$ However, this microfluidic adaptation is only suitable for analyzing cells that have been prepared in advance and then introduced into a microfluidic platform. For a wider applicability of the technique in a microfluidic environment, for instance, by combining perfusion culture and analysis of genetically modified cells, "wiring" and immobilization of cells is not suitable. Here, we performed an assay on redox metabolism using the soluble mediators, menadione (intracellular accessibility) and ferricyanide (extracellular secondary mediator) directly after electrochemical impedance spectroscopic (EIS) monitoring of cell sedimentation and evaluated the effect of flow rate on signal intensity.

DA is a neurotransmitter involved in several neurodegenerative disorders. ${ }^{25}$ Electrochemical detection of single vesicle exocytotic DA release has been pioneered by Wightman and coworkers using carbon fibre microelectrodes. ${ }^{31,32}$ The development of microfabrication techniques has opened possibilities for constructing novel electrodes and electroanalytical systems, giving rise to various technical developments for single cell neurotransmitter detection. ${ }^{33,34}$ Measurements at single cell level provide valuable information about the mechanism of exocytosis and effect of drugs. However, the experimental procedures are labour intensive, limiting the available information. On the other hand, monitoring of exocytosis on cell population level can provide facile screening of drug effects ${ }^{35}$ and characterization of neural stem cells developed for cell replacement therapy of neurodegenerative diseases. ${ }^{36}$ The development of electrochemical methods and analysis platforms for population based neurotransmitter detection, specifically for DA, is a new emerging field ${ }^{25,35-38}$ with scarce applications in microfluidic environment. ${ }^{29,39-43}$ We measured DA release from PC12 cells induced by both chemical and mechanical (increased flow rate) stimulation in the microfluidic environment after EIS monitoring of cell adhesion and growth.

\section{Results and discussion}

\section{Assessment of the on-line cleaning of the electrodes}

Cleaning of electrode surfaces represents a crucial step in order to assure reproducibility and stability of electrochemical detection. The optimized cleaning procedure for Au electrodes, as previously presented elsewhere, comprises both a chemical and electrochemical step. ${ }^{\mathbf{4 4 , 4 5}}$ The complete cleaning, as evaluated in an electrochemical batch cell, renders electrodes with a highly reproducible behaviour. ${ }^{25,26}$ During system assembly (as described in the Experimental section), each microelectrode chip undergoes chemical cleaning prior to integration with microfluidics, since it is not amenable for a closed microfluidic system due to strong gas evolution during the process. The electrochemical cleaning, which can instead be easily performed on-line after complete assembly of the platform, removes possible contaminations due to the attachment of the silicon adhesive gasket.

Based on our tests, the combination of chemical cleaning of microelectrode chips prior to integration and on-line electrochemical cleaning after integration (detailed description in the Experimental section) provides optimal electrode reproducibility. Moreover, electrodes that have been used for a cell based assay can be re-cleaned afterwards using the on-line electrochemical procedure.

Table 1 presents a summary of electrode characterization comparing the cyclic voltammetric behaviour (probed using 
$10 \mathrm{mM}$ ferricyanide/ferrocyanide) of already used working electrodes (WEs) before recleaning has been performed and the same electrodes after the electrochemical on-line cleaning followed by Cys modification. The results indicate that all the aspects defining optimal electrode behaviour for electrochemical assays, i.e. peak separation, peak current and reproducibility of the obtained current response, are re-established and significantly improved.

The results in Table 1 show that the platform allows, aside from carrying out and monitoring the electrochemical cleaning after integration, reusability of the integrated electrodes. All the re-cleaning and re-functionalization steps can be performed online by introducing different solutions in the chambers and applying a required potential to the electrodes without disassembling the platform.

\section{Monitoring of yeast cell sedimentation and intracellular redox metabolism}

When seeding yeast cells into miniaturized devices in preparation for experiments involving electrochemical monitoring, a sufficient time has to be allocated for cell sedimentation. ${ }^{\mathbf{3 0 , 4 4}}$ We have previously shown the suitability of EIS for monitoring the progress of yeast cell sedimentation $^{44}$ as a means to evaluate when the cell seeding is complete allowing initiation of the assay. After yeast sedimentation was achieved, the amperometric monitoring of the intracellular redox metabolism was performed under microfluidic conditions by using the menadione/ferricyanide double mediator system. ${ }^{29}$

\section{EIS monitoring of yeast cell seeding}

After loading the microfluidic chambers with yeast suspension, the progress of cell seeding was first monitored over time (every 5 min) unto the Cys modified electrodes, ${ }^{\mathbf{4}}$ by acquiring impedance spectra in PBS containing an equimolar amount of ferri/ferrocyanide. Fig. 1A shows the recorded spectra as Nyquist plots, which show the characteristic electrode-electrolyte interface behaviour under a faradaic process, i.e. kinetic and mass transfer limitation represented by charge

Table 1 Peak separation and peak current (oxidation and reduction) for Cys modified WEs of a microelectrode chip probed by $10 \mathrm{mM}$ ferricyanide/ferrocyanide in PBS. Each side of the 8 IDEs was characterized separately. $(n=16)$

\begin{tabular}{|c|c|c|}
\hline Determined parameter & $\begin{array}{l}\text { Before } \\
\text { recleaning }\end{array}$ & $\begin{array}{l}\text { After recleaning/Cys } \\
\text { modification }\end{array}$ \\
\hline Peak separation (mV) & 709 & 90.8 \\
\hline $\begin{array}{l}\text { Peak separation variability } \\
\text { (RSD\%) }\end{array}$ & $17 \%$ & $7.2 \%$ \\
\hline Oxidation peak current $(\mu \mathrm{A})$ & 1.58 & 3.23 \\
\hline $\begin{array}{l}\text { Oxidation peak current } \\
\text { variability }(\mathrm{RSD} \%)\end{array}$ & 8.2 & 2.4 \\
\hline Reduction peak current $(\mu \mathrm{A})$ & -1.57 & -3.18 \\
\hline $\begin{array}{l}\text { Reduction peak current } \\
\text { variability (RSD\%) }\end{array}$ & 9.5 & 4.9 \\
\hline
\end{tabular}
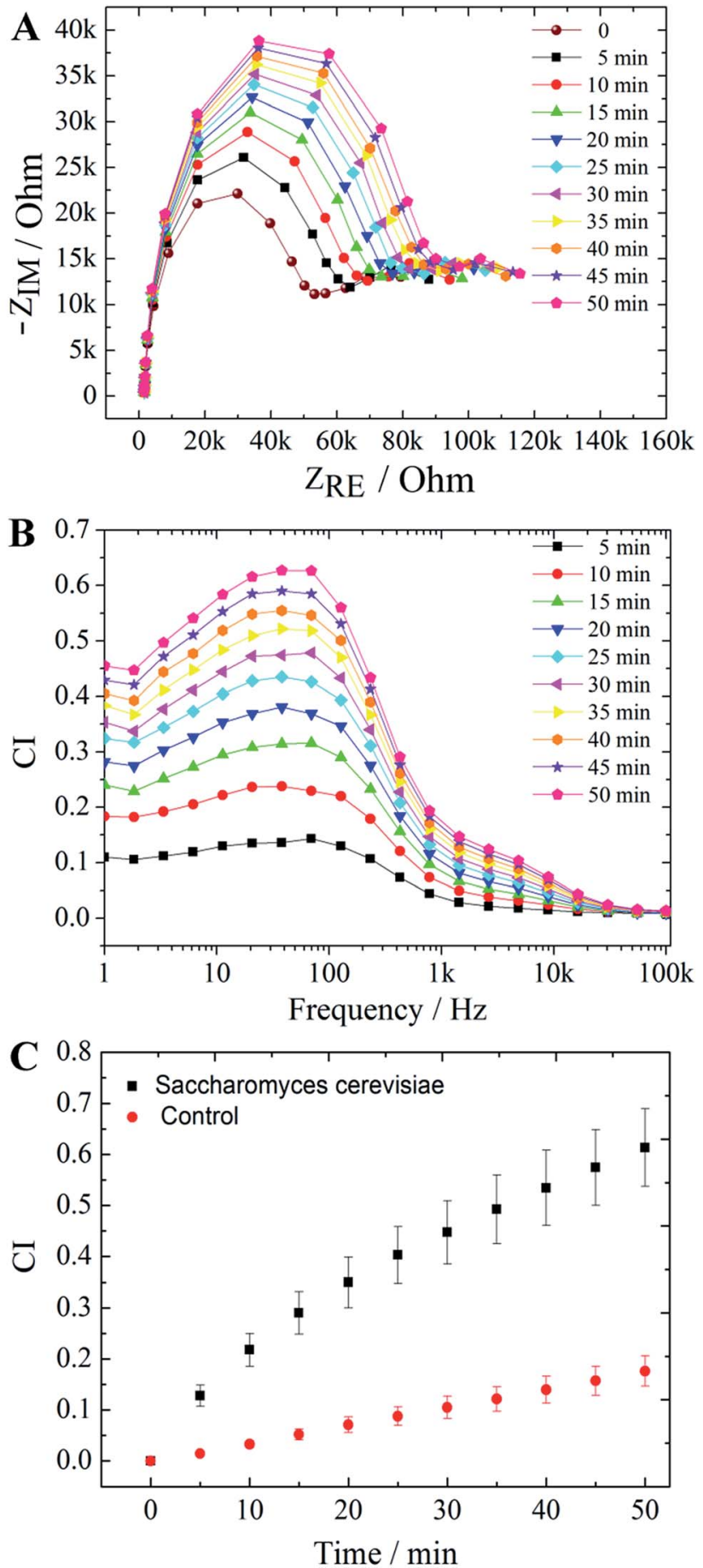

Fig. 1 EIS monitoring of Saccharomyces cerevisiae seeding with time: (A) Nyquist plots acquired during cell sedimentation $\left(Z_{I M}\right.$ and $Z_{R I}$ represent the imaginary and real part of the impedance, respectively); (B) normalized impedance spectra (Cl) of cell sedimentation; (C) variation of $\mathrm{Cl}$ at $57 \mathrm{~Hz}$ in three chambers with $1250 \pm 228$ cells per $\mathrm{mm}^{2}$ and three control chambers in the absence of cells. Error bars represent SD $(n=3)$. Impedance spectra were recorded in the frequency range $1 \mathrm{~Hz}$ to $100 \mathrm{kHz}$ every 5 minutes in PBS containing 10 $\mathrm{mM}$ ferri/ferrocyanide.

transfer resistance $\left(R_{\mathrm{ct}}\right)$ and Warburg impedance $\left(Z_{\mathrm{W}}\right)$, respectively. Generally, at solid electrodes such interfaces can be modelled using the Randles equivalent circuit $^{46}$ modified 
by replacing the double layer capacitance by the constant phase element (CPE). ${ }^{47}$

This general behaviour is represented by the first Nyquist plot recorded immediately after cell loading $(t=0)$ when only a fraction of the cells had sedimented onto the electrodes. The subsequent spectra, acquired during the continued deposition of yeast cells at the bottom of the chamber, show an increase in the $R_{\mathrm{ct}}$ due to the decreasing free electrode area. However, an increasing deviation can be observed from the behaviour described by the modified Randles equivalent circuit, characterized by the low-frequency bending of the $Z_{\mathrm{W}}$ line. To model such spectral behaviour, a more detailed equivalent circuit is required ${ }^{44}$ To simplify data analysis, instead of using curve fitting to an equivalent circuit, quantitative progress of cell sedimentation can be determined by normalizing impedance spectra (presented in Fig. 1B as Cell Index, CI, with detailed description in the Experimental section). The average CI values for three microfluidic chambers vs. time presented in Fig. 1C were calculated from the normalized spectra (Fig. 1B) at $57 \mathrm{~Hz}$. Although the average CI for three control chambers without cells shows a positive drift, the trend is linear in contrast with the one for the cell loaded chambers which is levelling off.

\section{Flow rate dependent signal intensity of yeast redox metabolism}

In microfluidic applications on monitoring of cellular redox metabolism, ${ }^{29,30}$ the magnitude of the recorded current is dependent on a quantitative transfer of the electrons vested from the cellular redox metabolism to the electrode. In our previous application using cell "wiring" with the polymeric mediator (redox active osmium polymer), the electrons were shuttled effectively (by the formed menadiol) from the cellular redox metabolism to the electrode through the redox centres of the polymer where the cells were anchored.$^{30}$ Hence, the maximal current response was not significantly dependent on the applied flow rate. However, when the secondary mediator (ferricyanide) is soluble, ${ }^{29}$ it may be partially flushed away before it can be detected at the electrode surface. This can result in a response that does not accurately reflect the cellular redox metabolism.

We monitored yeast redox metabolism, demonstrating specifically the influence of flow rate on the recorded current response. Fig. 2A shows the dynamics of recorded current in four different chambers. One chamber without cells was used as control (red line) and the three other chambers were loaded with the same amount of cells $\left(1250 \pm 228\right.$ cells per $\left.\mathrm{mm}^{2}\right)$. The black line shows the average of the response recorded in the three chambers, while the grey band represents the standard deviation between the measurements. A stable baseline was obtained when PBS was perfused through the system at

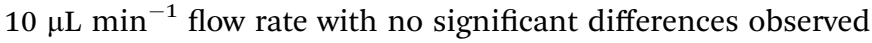
between the chambers (control or those loaded with cells). When $2 \mathrm{mM}$ ferricyanide was introduced into the chambers (indicated as F), the current in the presence of yeast cells reached a rather small but stable level, indicating the redox activity related to membrane bound redox enzymes since
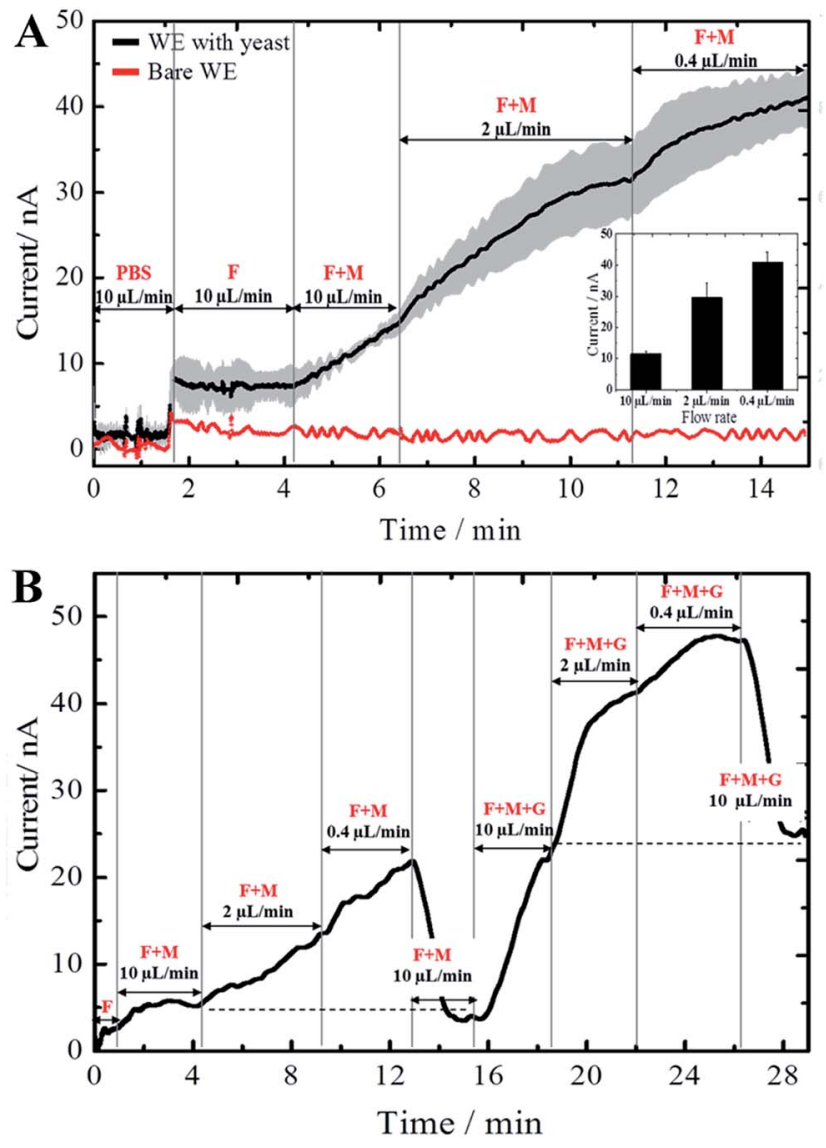

Fig. 2 (A) An averaged current-time recording for three S. cerevisiae populations each monitored in a different chamber (black line). The grey band represents the SD. The control current-time trace was recorded in a microfluidic chamber without cells (red line). Inset: the signal variation with changing flow rate in the presence of $F$ and $M$. (B) Current response of a $S$. cerevisiae population in the presence of $F, M$, and $G$ at different flow rates ( $F$, ferricyanide; $M$, menadione; $G$, glucose; $F+M$ : basal level of redox activity; $F+M+G$ : redox activity upon accelerated metabolism). Each arrow marks the period of a specific flow rate. The signal intensity is dynamically changing with the flow rate. WEs were biased at $+350 \mathrm{mV}$ vs. on-chip Au RE.

ferricyanide is not able to diffuse through the plasma membrane into the intracellular environment. Introduction of buffer also containing $100 \mu \mathrm{M}$ menadione (indicated as $\mathrm{F}+\mathrm{M}$ ) increased the current response now reflecting the involvement of the intracellular redox metabolism which was further increased upon gradually decreasing the flow rate from 10 to 0.4 $\mu \mathrm{L} \mathrm{min}{ }^{-1}$. The inset of Fig. 2A shows a comparison of the current responses at steady-state for each of the flow rates. Although decreasing the flow rate by a factor of 25 (from 10 to $0.4 \mu \mathrm{L} \mathrm{min}{ }^{-1}$ ) only corresponds to approximately 2.5 -time increase in the current response, the achieved effect is, nevertheless, significant for experiments where even a marginal enhancement in the observed dynamics can help distinguish between biological effects.

At the beginning of the measurement shown in Fig. 2B, the chambers were perfused at a flow rate of $10 \mu \mathrm{L} \mathrm{min}{ }^{-1}$ with PBS containing $2 \mathrm{mM}$ ferricyanide followed by the same buffer having $100 \mu \mathrm{M}$ menadione. When the flow rate was decreased 


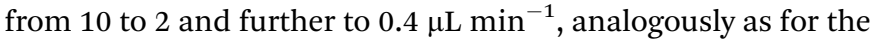
response curve in Fig. 2A, a gradual increase in the current could be observed. Upon returning back to the $10 \mu \mathrm{L} \mathrm{min} \operatorname{mon}^{-1}$ flow rate the current is decreased, reaching the same level previously obtained for that flow rate. This indicates that the mapped basal level of redox activity is under steady state control, the variation in current being only dependent on the applied flow rate. After $16 \mathrm{~min}$, a $10 \mathrm{mM}$ glucose solution was perfused through the system, resulting in an acceleration of redox metabolism due to increased availability of $\mathrm{NAD}(\mathrm{P}) \mathrm{H}$ indicated by the further increase in current. As observed for the basal level of redox metabolism when only menadione and ferricyanide were present, the administered glucose leads to a steady state of redox metabolism, the current level being influenced only by the applied flow rate.

Detection is only possible if menadione is reduced intracellularly and reoxidized forming ferrocyanide that can reach the electrode surface to be oxidized. Our previous study using polymeric mediator showed that a high current response is obtained even at a higher flow rate, such as $10 \mu \mathrm{L} \mathrm{min}{ }^{-1}$. This means that the observed current dynamics, i.e. a low current response at a higher flow rate is not caused by the cellular metabolism. Hence, the increased current response at a decreased flow rate can be explained by the fact that the removal of the mediators is slower, i.e. a greater fraction of the formed ferrocyanide is reoxidized at the electrode surface resulting in the higher current.

This experiment further highlights the necessary aspects of redox metabolism assays in relation to the functional features of the platform: (1) a fast flow rate is initially needed to promptly deliver a solution (an additional mediator or cellular effector) to the microfluidic chamber and equilibrate the concentration to have a well-defined response. (2) A change in the flow rate is required to enhance the current. Such flow conditions with prompt and precise changes in flow rate, without interrupting the flow, are readily achieved using the LabView programmable micropumps integrated on the platform (presented in the Experimental section).

\section{Monitoring of PC12 cell growth and detection of DA exocytosis}

In neurotransmitter detection assays in microfluidics, the effect of possible mechanical perturbations is usually not taken into consideration. Therefore, we performed and compared the effect of both chemical and mechanical stimulation of PC12 cells and quantified the released DA. Prior to and after the DA detection, the adhesion and proliferation of PC12 cells was monitored in real-time for evaluating the condition of the cell population.

\section{EIS monitoring of PC12 cell growth}

Preparation of cell based electrochemical experiments to be conducted in a microfluidic environment requires optimization of cell coverage on the electrodes. Aside from diverse applications, such as toxicological evaluation, ${ }^{15,48}$ EIS monitoring functions as a tool to assess cell adherence ${ }^{15}$ on electrodes in preparation for further bioassays, such as exocytosis detection from cell populations.

PC12 cells were seeded using suspensions with different cell densities (from 1.5 to 3 million cells per $\mathrm{mL}$ ) in order to find an optimal density, which gives uniform cell coverage on the WEs. We found a correlation between the initial cell density in the seeding suspension and the number of cells on the WEs in the microfluidic chambers (Fig. 3A). The optimal density of seeded PC12 cells was 3 million cells per $\mathrm{mL}$, resulting in uniform coverage on the WEs $(270 \pm 34$ cells per WE area; average \pm SD, $n=3$ ). This cell density was similar to the one used earlier by Sasso et al. ${ }^{25}$ when measuring DA release from populations of PC12 cells in a batch system using the same electrode design.

After cell seeding, PC12 cells were kept at stopped flow condition to facilitate adhesion. The EIS monitoring was performed at $250 \mathrm{~nL} \min ^{-1}$ flow rate, which does not have any influence on EIS recordings as indicated by the overlapping Bode plots in Fig. 3B. Impedance spectra were recorded once an hour by applying a $200 \mu \mathrm{V}$ sinusoidal potential. Fig. 3D shows a characteristic growth curve presented as CI vs. time. The adhesion and migration of the PC12 cells was observed during the first $5-10 \mathrm{~h}$ of the EIS monitoring followed by an increase in CI until $25 \mathrm{~h}$ before reaching a plateau. After having reached the steady-state in the growth curve at $25 \mathrm{~h}$, an exocytosis measurement could have already been initiated. In this case, the EIS monitoring was, however, continued until $45 \mathrm{~h}$, where a typical decreasing trend could be seen until $32 \mathrm{~h}$, indicating the low adhesion and clustering/partial detachment of PC12 cells, ${ }^{\mathbf{4 9}}$ followed by a steady-state up to $45 \mathrm{~h}$. After a conducted exocytosis measurement (discussed below), the impedance recording was continued. Now, the starting CI level was clearly below the value that had been reached at $45 \mathrm{~h}$, showing only a slow increase in CI (Fig. 3D).

This drastic effect in the CI level could be due to the changes during exocytosis measurements in the biological condition (e.g., exposure of the cell population to room temperature and lack of serum proteins in the assay buffers that further deteriorates cell adhesion) affecting the subsequent impedance measurements. The presented study illustrates significant points when using EIS as a tool in preparation for cell based experiments: it provides a possibility to assess in real-time the condition of cell cultures to (1) ensure the best timing for continued experiments, and (2) evaluate the effect of experimental conditions on the cell population.

\section{Amperometric monitoring of DA exocytosis}

Based on previous studies on collagen coated electrodes, ${ }^{35}$ the extracellular matrix protein coating was considered to decrease the efficiency of DA detection. We found that the electrochemical detection of DA on laminin coated electrodes is improved compared to bare electrodes (Fig. 3C). The applied potential for DA detection ( $E_{\mathrm{app}}=400 \mathrm{mV} v s$. on-chip Au RE) was chosen based on the cyclic voltammogram on laminin modified electrode (Fig. 3C) in order to have sufficient overpotential for DA oxidation. Detection of DA release from the PC12 cell population (Fig. 3D) was performed after $45 \mathrm{~h}$ of cell 
A

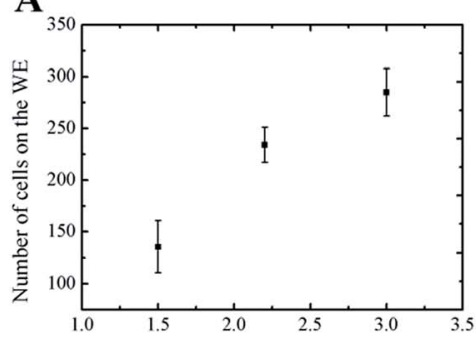

Seeded cell density (milion cells $/ \mathrm{mL}$ )

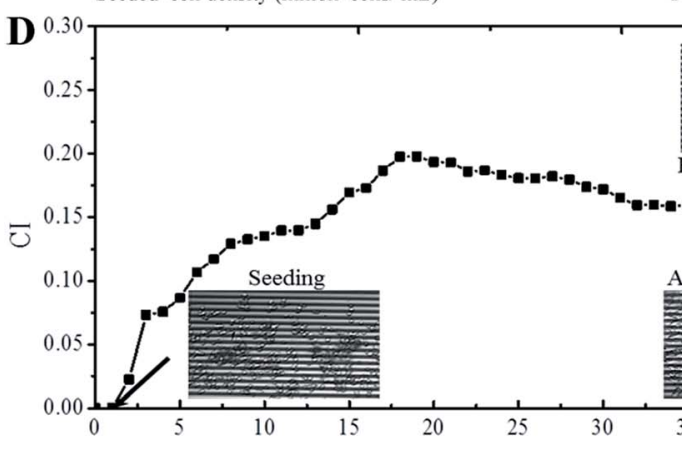

B

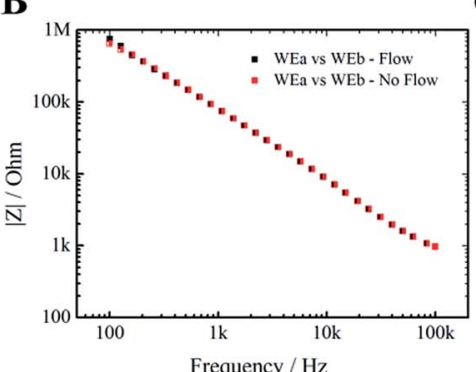

C

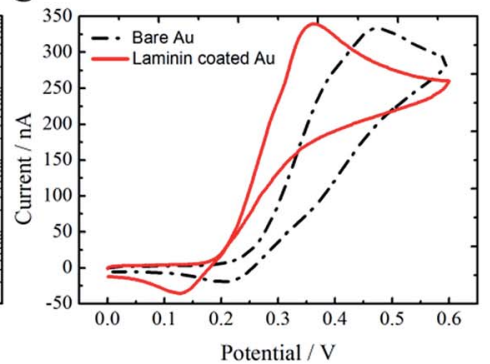

Fig. 3 (A) Correlation between the number of PC12 cells in suspension and number of cells on the WEs. The error bars represent SD ( $n=3$ ). (B)

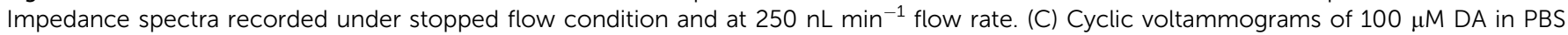
recorded before and after laminin modification. (D) Impedance monitoring of PC12 cell adhesion and growth. Inserts: (i) representative images of PC12 cells on the WE; (ii) detection of DA release from the cell population induced by elevated $\mathrm{K}^{+}$perfused at $1 \mu \mathrm{L} \mathrm{min}^{-1}$ flow rate $\left(E_{\mathrm{app}}=400 \mathrm{mV}\right.$ vs. on-chip Au RE).

growth by introducing buffer containing elevated $\mathrm{K}^{+}$concentration $\left(1 \mu \mathrm{L} \min ^{-1}\right.$ flow rate) into the cell culture chamber. The current response due to oxidation of the released DA (Fig. 3D inset) starts when the elevated $\mathrm{K}^{+}$buffer enters the cell culture chamber in the vicinity of the WE and lasts for approximately the period corresponding to the passage of the buffer over the

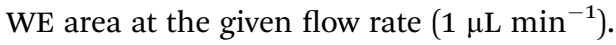

Aside from DA exocytosis induced by elevated $\mathrm{K}^{+}$, we also recorded current-time traces related to DA release induced mechanically by increasing the flow rate from $1 \mu \mathrm{L} \mathrm{min}{ }^{-1}$ to $10 \mu \mathrm{L} \mathrm{m^{-1 }}$ for $10 \mathrm{~s}$ (Fig. 4A). The flow rates were chosen based on calculations performed to evaluate the effect of shear stress at different flow rates indicating that $1 \mu \mathrm{L} \mathrm{min}{ }^{-1}$ does not cause any adversary effect on the cells ${ }^{13,50,51}$ while $10 \mu \mathrm{L} \min ^{-1}$ generates a shear stress level of $12 \mathrm{mPa}$. When comparing the current responses from $\mathrm{K}^{+}$and mechanically induced DA release, we observed that both the charge (Fig. 4B) calculated by integrating the area of the current peak ${ }^{25}$ and duration of DA release (Fig. 4C) are much lower in the case of mechanical induction while the peak heights are similar (Fig. 4D). The quantity (charge) of released DA is much lower in the case of mechanical induction as reported earlier in the case of single cell exocytotic events. ${ }^{31,52}$

The used flow rate for neurotransmitter detection from populations of PC12 cells in a microfluidic environment varies depending on the structure of the microfluidic chamber/ channel where the cells reside. ${ }^{39-43}$ Our results indicate that when chemical stimulation is to be used it is significant to optimise the flow conditions in order to avoid mechanical stimulation, however, this aspect is not commonly addressed in publications.

To further explore the experimental possibilities of the platform, we monitored DA depletion from the same population of PC12 cells (Fig. 4E). There is a drastic decrease in both peak height and charge between the first and second $\mathrm{K}^{+}$induced DA release, followed by a gradually decreasing signal when the cells were mechanically stimulated using high- $\mathrm{K}^{+}$buffer showing the DA depletion of the cells.

\section{Experimental}

\section{The EXCELL platform}

The fully integrated EXCELL platform is shown in Fig. 5 with (A) and without (B) the EXCELL potentiostat attached. The EXCELL platform is equipped with: (1) a base plate to accommodate all the necessary components, (2) four 8-channel peristaltic micropumps ${ }^{24}$ operated with Lego® Interactive servo motors connected to NXT Intelligent Brick units (Lego Systems A/S, Billund, Denmark) under control of the custom-made LabView-based EXCELL software, (3) four 8-channel pump ribbons in poly(dimethylsiloxane) (PDMS), ${ }^{24}$ (4) four different sample and/or waste reservoirs and (5) a 'plug-in' microfluidic chip with integrated 12-microelectrode array chip (Fig. 5C) with the capability to electrochemically address 12 separate cell culture chambers (Fig. 5D) individually, monitoring 12 different cell populations. The EXCELL potentiostat was operated by the custom-made EXCELL acquisition and analysis software that enables different electrochemical techniques (e.g., cyclic 
A

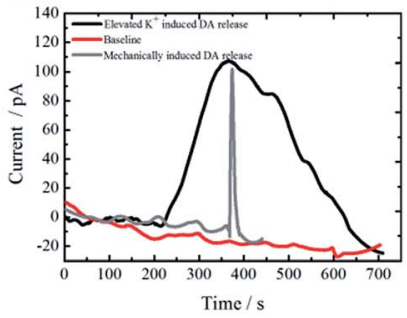

B

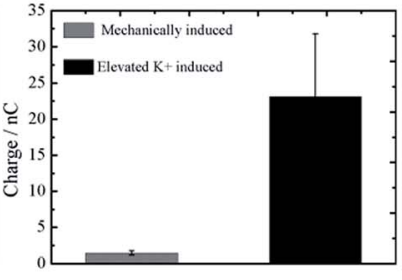

C

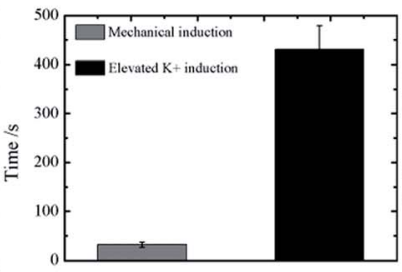

D

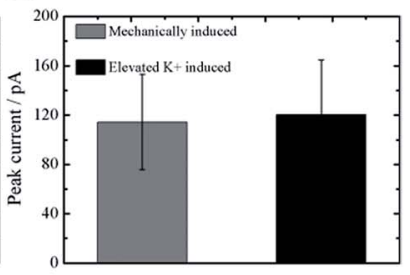

$\mathbf{E}$

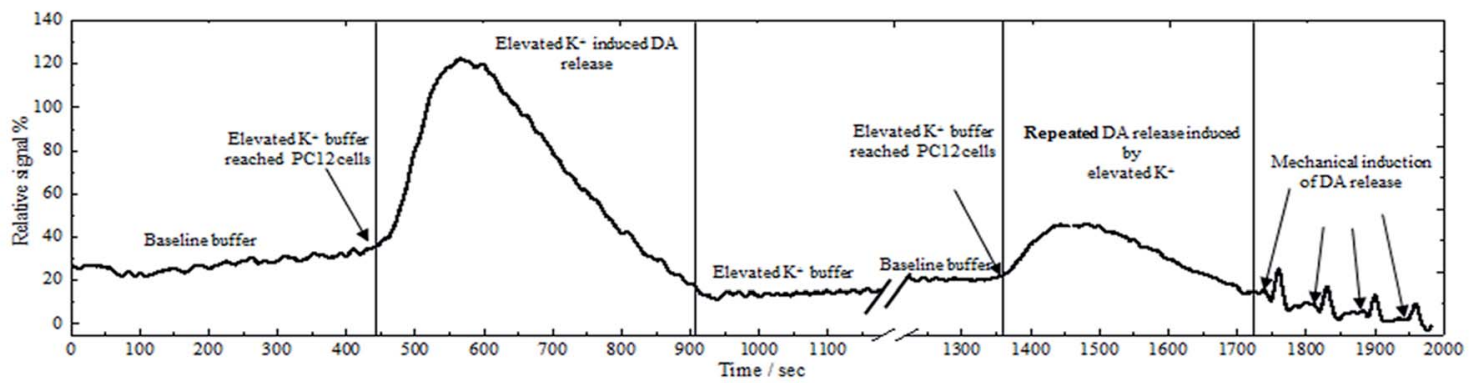

Fig. 4 (A) A typical current-time trace recorded during DA release from PC12 cells induced by elevated (150 mM) $\mathrm{K}^{+}$concentration perfused at 1 $\mu \mathrm{L} \mathrm{min}^{-1}$ flow rate (black line), and mechanical pulse (increased flow rate, $10 \mu \mathrm{L} \mathrm{min}{ }^{-1}$ ) for $10 \mathrm{~s}$ (grey line). The control represented as baseline trace was recorded in a chamber without cells (red line) under perfusion at $1 \mu \mathrm{L} \mathrm{min}{ }^{-1}$ flow rate. (B) Charge corresponding to the amount of released $D A,(C)$ duration of DA release, and (D) peak height were determined for both $\mathrm{K}^{+}$and mechanically induced $\mathrm{DA}$ release from three independent populations of PC12 cells. The error bars represent SD. (E) Dynamic monitoring of DA depletion from a population of PC12 cells. (All amperometric recordings were acquired from a similar number of cells while the WEs were biased at $+400 \mathrm{mV} v s$. on-chip Au RE.)

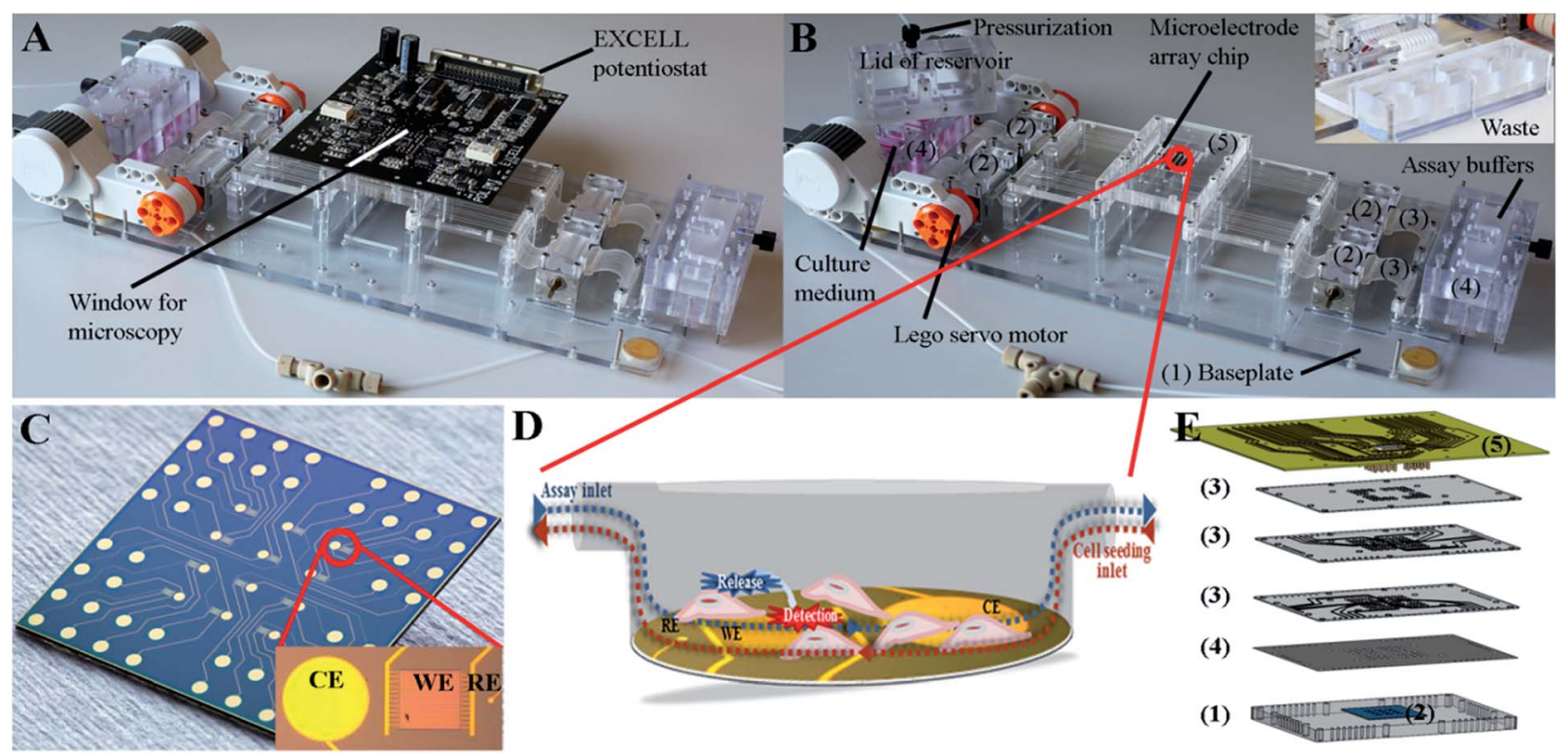

Fig. 5 Photographs of the fully integrated EXCELL cell culture and analysis platform (A) with the 12-channel EXCELL bipotentiostat and (B) without the potentiostat showing the microfluidic cell culture chip (5) with integrated microelectrode arrays. The baseplate (1) houses: 4 peristaltic micropumps (2) with PDMS pump ribbons (3) (operated by Lego $®$ servo motors); pressurized reservoirs for culture medium, assay buffers and waste (4) (gas for pressurization is led through the lids). (C) A photograph of a 12-microelectrode array chip (insert: a microscopic image of one measurement site with 3-electrode configuration showing the counter (CE), working (WE) and reference electrode (RE)). (D) A schematic representation of an individual cell culture chamber in the microfluidic cell culture array chip (the microelectrode array chip forms the bottom of the chamber). (E) An illustration of the assembly of a microfluidic cell culture array chip: the 5 mm PMMA support (1) houses fluidic connections to the platform and a microelectrode array chip (2), which is integrated to the microfluidic cell culture array chip (3) (composed of three $500 \mu \mathrm{m}$ PMMA layers through a $50 \mu \mathrm{m}$ laser-cut double adhesive silicon gasket (4). Electric connections between the microelectrode array chip and the EXCELL potentiostat (5) are formed using spring loaded pins. 
voltammetry, amperometry and electrochemical impedance spectroscopy (EIS)). ${ }^{27}$ Data acquisition was done through a portable NI-6259 USB system (National Instruments Corporation, Austin, TX, USA).

To avoid bubble formation, the platform was pressurised (Fig. 5B) through connections integrated in the lid of each reservoir ( 0.4 bar overpressure provided by a gas mixture composed of $5 \% \mathrm{CO}_{2} / 20 \%$ oxygen $/ 75 \%$ nitrogen supplied by AGA A/S, Copenhagen, Denmark). Each gas connection was established using a $6 \mathrm{~mm}$ HPLC connector and equipped with a $0.5 \mu \mathrm{m}$ cut-off filter unit (all components from IDEX Health \& Science SA, Glattbrugg, Switzerland) to avoid contamination and infection during perfusion culture. The connection between sample/waste reservoirs, and the plug-in microfluidic array chip was achieved through the peristaltic pumps via the PDMS multichannel ribbons. ${ }^{24}$

All the polymeric components of the platform were designed using AutoCAD 2013 (Autodesk, Inc., San Rafael, CA, USA), machined by micromilling using a Mini-Mill/3PRO system (Minitech Machinery Corporation, Norcross, GA, USA) executing G-code generated by EZ-CAM17 Express software (EZCAM Solutions, Inc., New York, NY, USA) and thermally bonded $\left(20 \mathrm{~min}\right.$ at $85{ }^{\circ} \mathrm{C} / 4.4 \mathrm{MPa}$ using a PW20 hydraulic press from Paul-Otto Weber GmbH, Remshalden, Germany) after 1 min UV activation (5000-EC Series UV Curing Flood Lamp System from Dymax Corporation, Torrington, CT, USA).

\section{Microfluidic cell culture chip with integrated microelectrode array}

The microfluidic cell culture chips, composed of three $500 \mu \mathrm{m}$ thick poly(methyl methacrylate) (PMMA) layers with microfluidic channels, were micromilled and bonded as described above (schematically shown in Fig. 5E). The chips with 12 microelectrode arrays (Fig. 5C), each consisting of a working (WE), counter (CE) and reference (RE) electrode, were fabricated on a wet oxidized 4-inch Si wafer (one side polished) using UV lithography with a lift-off process as previously described..$^{26}$ The $\mathrm{Au}$ WEs are interdigitated electrodes (IDE) with twelve $500 \mu \mathrm{m}$ long and $10 \mu \mathrm{m}$ wide digits (gap: $10 \mu \mathrm{m}$ ). Both the CEs and REs are Au disks with $700 \mu \mathrm{m}$ and $50 \mu \mathrm{m}$ diameter, respectively.

Prior to integration, the microelectrode array chip was chemically cleaned in a mixture of $25 \% \mathrm{H}_{2} \mathrm{O}_{2}$ and $50 \mathrm{mM}$ $\mathrm{KOH}^{44,45}$ The integration (Fig. $5 \mathrm{E}$ ) was done by placing the microelectrode array chip in a $5 \mathrm{~mm}$ PMMA holder and attaching it to the microfluidic cell culture chip using a silicon adhesive gasket (INT TA106) (Intertronics, Oxfordshire, UK) cut with laser ablation (48-5S Duo Lase carbon dioxide laser, Synrad Inc., Mukilteo, WA, USA) in order to form the cell culture/ detection chambers (Fig. 5D) facilitating cell seeding and assays.

\section{Chemicals}

Potassium hydroxide (semiconductor grade), sodium hydroxide, potassium chloride, potassium hexacyanoferrate(II) (ferrocyanide), potassium hexacyanoferrate(III) (ferricyanide), and glucose (all BioXtra grade), sodium chloride, magnesium chloride hexahydrate, calcium chloride dihydrate, hydrochloric acid, and 4-(2-hydroxyethyl)piperazine-1-ethanesulfonic acid (HEPES; 1 M solution) (all BioReagent grade), hydrogen peroxide $(30 \%$ solution in water), cysteamine hydrochloride (Cys), menadione, 2-(3,4-dihydroxyphenyl)ethylamine hydrochloride (dopamine), 3-(3,4-dihydroxyphenyl)-L-alanine (L-DOPA), laminin from Engelbreth-Holm-Swarm murine sarcoma basement membrane, polyethylenimine (PEI, branched, average $M_{\mathrm{w}} \sim 25000$ ), horse serum (HS), fetal bovine serum (FBS), cell culture tested phosphate buffered saline (PBS) and water were all purchased from Sigma Aldrich Corporation (St. Louis, MO, USA). Dulbecco's Modified Eagle Medium/Ham's Nutrient Mixture F12 with GlutaMAX (DMEM/F12), trypsinEDTA (0.05\%), and penicillin/streptomycin (P/S) were purchased from Life Technologies Ltd (Paisley, UK). The aqueous solutions used in experiments on PC12 cells were prepared in cell culture tested water. All other aqueous solutions were prepared in ultrapure water (resistivity 18.2 Mohm $\mathrm{cm}$ ) obtained from a Milli-Q ${ }^{\circledR}$ water purification system (Millipore Corporation, Billerica, MA, USA).

\section{On-line electrode cleaning, functionalization and sterilization}

After integration of a microelectrode chip with a microfluidic cell culture chip and assembly of the platform, an on-line electrochemical cleaning (potential sweep from $-200 \mathrm{mV}$ to $-1200 \mathrm{mV} v s$. on-chip $\mathrm{Au} \mathrm{RE}$ at a $50 \mathrm{mV} \mathrm{s}^{-1}$ scan rate in $50 \mathrm{mM} \mathrm{KOH}{ }^{\mathbf{4 4 , 4 5}}$ ) was performed to ensure optimal function of the electrode arrays. The cleaning procedure was followed by on-line functionalization step necessary to ensure optimum conditions for the experiments. Yeast redox metabolism was monitored on electrodes functionalized with a self-assembled monolayer (SAM) of Cys (200 mM, 2 h, stopped-flow) shown to enhance the interaction between electrodes and yeast cells. ${ }^{44}$ In preparation for PC12 cell culturing and detection of DA exocytosis, the microfluidic cell culture platform was cleaned and sterilized using $500 \mathrm{mM} \mathrm{NaOH}$ introduced at $30 \mu \mathrm{L} \mathrm{min}{ }^{-1}$ followed by $20 \mathrm{~min}$ perfusion at $5 \mu \mathrm{L} \mathrm{min}{ }^{-1}$ flow rate. After sterilization, the $\mathrm{NaOH}$ solution was removed from the platform

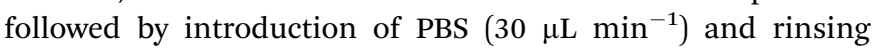
$\left(15 \mu \mathrm{L} \mathrm{m^{-1 }}{ }^{-1}\right.$ for $30 \mathrm{~min}$. All the subsequent steps were performed under sterile conditions. For enhanced cell adhesion, the microelectrode arrays were coated with laminin $\left(20 \mu \mathrm{g} \mathrm{mL}^{-1}\right.$ in PBS, $2 \mathrm{~h}$ at $37^{\circ} \mathrm{C}$ in an incubator) at a constant flow rate of $250 \mathrm{~nL} \min ^{-1}$ under pressurization. The excess laminin solution was removed followed by rinsing with PBS $\left(15 \mu \mathrm{L} \mathrm{min}{ }^{-1}\right.$, $20 \mathrm{~min}$ ). All the on-line cleaning and functionalization steps were performed using aqueous solutions that are compatible with PMMA. The microfluidic chips with integrated electrode chip were used once after re-cleaning.

\section{Yeast sedimentation and intracellular redox activity assay}

Saccharomyces cerevisiae cells (baker's yeast from Jästbolaget AB, Sweden) were suspended at a density of $10 \mathrm{mg} \mathrm{mL}^{-1}$ in PBS containing $10 \mathrm{mM}$ ferricyanide and ferrocyanide. The cell suspension was placed in the outlet reservoirs of the platform. Cell loading was performed under continuous microscopic 
monitoring (Zeiss Axio Imager M1m microscope from Carl Zeiss AG, Göttingen, Germany) using reverse flow $\left(7 \mu \mathrm{L} \min ^{-1}\right.$, $15 \mathrm{~min}$ ) from the outlet reservoirs (Fig. 5B). After cell loading, the progress of cell seeding (sedimentation on the electrodes) was monitored with EIS for $50 \mathrm{~min}$ at $5 \mathrm{~min}$ measurement interval using the EXCELL potentiostat/software $(1 \mathrm{mV}$ sinusoidal potential applied in the frequency range $1 \mathrm{~Hz}$ to $100 \mathrm{kHz}$, 10 data points per decade) based on a protocol developed for static conditions. ${ }^{44}$ The amperometric monitoring of intracellular redox activity was based on a method previously developed by Heiskanen et al. using the menadione/ferricyanide double mediator system. ${ }^{53}$ This assay monitors the dynamics in the $\mathrm{NAD}(\mathrm{P})^{+} / \mathrm{NAD}(\mathrm{P}) \mathrm{H}$ pool via the lipophilic mediator (menadione) that freely diffuses into the intracellular environment, where it is reduced to menadiol by menadione reducing enzymes. The lipophilic menadiol can diffuse back into the extracellular environment, where it is reoxidized by the secondary hydrophilic mediator, ferricyanide. The current recorded at the electrode surface due to oxidation of the formed ferrocyanide is an indicator of the cellular reducing capacity related to the availability of $\mathrm{NAD}(\mathrm{P}) \mathrm{H} .{ }^{28}$ In the assay, the microfluidic chambers were initially filled with PBS followed by sequential addition of PBS containing $2 \mathrm{mM}$ ferricyanide, $100 \mu \mathrm{M}$ menadione and $10 \mathrm{mM}$ glucose. The amperometric measurements were performed at $+350 \mathrm{mV}$ vs. the on-chip Au RE.

\section{PC12 cell seeding, proliferation and DA exocytosis}

PC12 cells (Deutsche Sammlung von Microorganismen und Zellkulturen $\mathrm{GmbH}$, Braunschweig, Gemany) were subcultured in PEI coated ( $50 \mu \mathrm{g} \mathrm{mL}^{-1}$ in PBS, $2 \mathrm{~h}$ at room temperature) T25 culture flasks (Nunc A/S, Roskilde, Denmark) using growth medium (DMEM supplemented with 15\% HS, 2.5\% FBS, 1\% P/S and $0.5 \%$ HEPES). In preparation for microfluidic experiments, the cells were trypsinized from the culture flasks using trypsinEDTA, counted using a standard hemocytometer and suspended in culture medium to obtain a desired cell density. Cell seeding in the platform was done as described above for yeast experiments. After seeding, the cells were left to adhere at stopped flow condition for $2 \mathrm{~h}$ and thereafter cultured under perfusion at a flow rate of $250 \mathrm{~nL} \mathrm{m^{-1 }}$ for at least $24 \mathrm{~h}$ before detection of DA exocytosis. Cell culturing was performed at $37^{\circ} \mathrm{C}$ in a humidified incubator at an atmosphere of $5 \% \mathrm{CO}_{2} /$ 95\% air.

After cell seeding, the progress of cell adhesion, spreading and proliferation was monitored for at least $24 \mathrm{~h}$ at $1 \mathrm{~h}$ measurement interval using EIS $(200 \mu \mathrm{V}$ sinusoidal potential applied in the frequency range $100 \mathrm{~Hz}$ to $100 \mathrm{kHz}, 10$ data points per decade). Prior to exocytosis experiments, PC12 cells were incubated in medium containing $100 \mu \mathrm{M}$ of the dopamine precursor L-DOPA ( $2 \mathrm{~h}$ at $250 \mathrm{~nL} \mathrm{~min}^{-1}$ flow rate) to increase the vesicular dopamine content. ${ }^{25}$ The L-DOPA containing medium was exchanged for low- $\mathrm{K}^{+}$buffer $(10 \mathrm{mM}$ HEPES, $5 \mathrm{mM}$ glucose, $1.2 \mathrm{mM} \mathrm{MgCl}_{2}, 2 \mathrm{mM} \mathrm{CaCl}_{2}, 150 \mathrm{mM} \mathrm{NaCl}$ and $5 \mathrm{mM} \mathrm{KCl}$ ) used for baseline recording. The baseline buffer was exchanged for high- $\mathrm{K}^{+}$stimulation buffer (the same composition as in the baseline buffer except for $150 \mathrm{mM} \mathrm{KCl}$ and $5 \mathrm{mM} \mathrm{NaCl}$ ).
Baseline recording and $\mathrm{K}^{+}$-induction of DA release were conducted at a flow rate of $1 \mu \mathrm{L} \min ^{-1}$, whereas mechanical induction was achieved by applying a $10 \mathrm{~s}$ flow pulse $(10 \mu \mathrm{L}$ $\min ^{-1}$ using baseline buffer). DA release was detected by oxidation on the WEs at $400 \mathrm{mV} v s$. on-chip Au RE. To facilitate recording of pA range currents CHI potentiostat (Model 1010A, $\mathrm{CH}$ Instrument Inc., Austin, TX, USA) was connected to the platform through a printed circuit board and used for all exocytosis measurements with shielded cables to minimize the random environmental noise.

Microscopic imaging during experiments was done using a Zeiss Axio Imager M1m microscope (Carl Zeiss AG, Göttingen, Germany) equipped with a Neo 5.5 sCMOS camera under control of Solis (i) software (version 4.22.30007.0) from Andor Technology Ltd. (Belfast, UK).

\section{Analysis of impedance data}

Impedance spectra acquired during experiments involving yeast and PC12 cells were expressed using the dimensionless parameter Cell Index (CI), ${ }^{48}$ which represents the maximum value of normalized impedance based on eqn (1).

$$
\mathrm{CI}(t)=\max _{i=1, \ldots, N}\left\{\left[\left|Z\left(t, f_{i}\right)\right|-\left|Z\left(0, f_{i}\right)\right|\right] /\left|Z\left(0, f_{i}\right)\right|\right\}
$$

where $\left|Z\left(t, f_{i}\right)\right|$ is the magnitude of impedance at a given frequency and time point and $\left|Z\left(0, f_{i}\right)\right|$ is the magnitude of impedance at the same frequency at the beginning of the experiment recorded in the absence of cells. For each time point, the CI was calculated by analysing the entire spectrum (10 points per decade).

\section{Conclusions}

Commonly used electrochemical microfluidic cell culture and detection devises are tailored for a specific application without providing operational flexibility for different cell based assays. The miniaturization of these devices is specifically targeting the cell culture unit/chip without considering the necessary functional parts, such as fluid handling and detection. Here, we have presented a microfluidic platform that represents a major step towards self-contained, robust analysis tools with integrated programmable fluid handling and electrochemical detection enabling automated long-term cell culturing and monitoring.

The presented biological work confirms the multifunctionality of the platform and forms the basis for further biological applications, such as drug-toxicity assays, study of stem cell differentiation combined with detection of signaling molecules, toxicological evaluation in environmental monitoring and screening of genetically modified microorganisms in strain engineering. Both the microfluidic chip and the integrated electrode chip can be redesigned to increase throughput in analysis and adaptation to a specific cell based assay, while maintaining the fluid handling and detection unit. Furthermore, using the presented prototyping the platform can be further miniaturized if needed for a specific application. Additionally, the in-built pressurization of the platform allows 
control of the gas composition $\left(\mathrm{CO}_{2}\right.$ level) to which cells are exposed in the microfluidic environment, providing incubatorfree culture conditions once a temperature control unit is incorporated.

\section{Acknowledgements}

This work was supported by the EU FP7 project EXCELL ("Exploring Cellular Dynamics at Nanoscale" NMP4-SL-2008214706). Additionally, the following agencies are acknowledged for financial support: Danish Council for Independent Research Natural Sciences (K.Z.), Lundbeck Foundation grant R69-A6408 (A.H.), and PhD scholarship from Department of Micro- and Nanotechnology, Technical University of Denmark (C.C. and F.S.). Haseena B. Muhammad is acknowledged for providing the illustration of the assembly of a microfluidic cell culture array chip and for sheer stress related calculations. Nanna Bild and Jesper Scheel are acknowledged for the graphical illustrations and photography.

\section{Notes and references}

1 D. Sabourin, P. Skafte-Pedersen, M. J. Søe, M. Hemmingsen, M. Alberti, V. Coman, J. Petersen, J. Emnéus, J. P. Kutter, D. Snakenborg, F. Jørgensen, C. Clausen, K. Holmstrøm and M. Dufva, J. Lab. Autom., 2013, 18, 212.

2 B. Li, L. Li, A. Guan, Q. Dong, K. Ruan, R. Hu and Z. Li, Lab Chip, 2014, 14, 4085.

3 D. Berg, in Oxidative Stress and Neurodegenerative Disorders, ed. G. A. Qureshi and S. H. Parvez, Elsevier, Amsterdam, 2007, p. 183.

4 K. Sas, H. Robotka, J. Toldi and L. Vécsei, J. Neurol. Sci., 2007, 257, 221.

5 M. F. Beal, Curr. Opin. Neurobiol., 1996, 6, 661.

6 V. P. Kramp, Neurodegener. Dis., 2012, 9, 210.

7 E. Michelini, L. Cevenini, L. Mezzanotte, A. Coppa and A. Roda, Anal. Bioanal. Chem., 2010, 398, 227.

8 K. Slater, Curr. Opin. Biotechnol., 2001, 12, 70.

9 M.-H. Wu, S.-B. Huang and G.-B. Lee, Lab Chip, 2010, 10, 939.

10 P. M. van Midwoud, E. Verpoorte and G. M. M. Groothuis, Integr. Biol., 2011, 3, 509.

11 J. P. Devadhasan, S. Kim and J. An, J. Biomed. Sci., 2011, 18, 33.

12 J. Y. Park, S. Takayama and S.-H. Lee, Integr. Biol., 2010, 2, 229.

13 R. Gómez-Sjöberg, A. A. Leyrat, D. M. Pirone, C. S. Chen and S. R. Quake, Anal. Chem., 2007, 79, 8557.

14 N. V. Kostesha, J. R. M. Almeida, A. R. Heiskanen, M. F. Gorwa-Grauslund, B. Hahn-Hägerdal and J. Emnéus, Anal. Chem., 2009, 81, 9896.

15 C. Caviglia, K. Zór, S. Canepa, M. Carminati, B. H. Muhammad, R. Raiteri, T. L. Andresen, A. Heiskanen and J. Emnéus, PLoS One, 2014, in review.

16 L. Nyholm, Analyst, 2005, 130, 599.

17 X. Xu, S. Zhang, H. Chen and J. Kong, Talanta, 2009, 80, 8.

18 F. Sassa, K. Morimoto, W. Satoh and H. Suzuki, Electrophoresis, 2008, 29, 1787.
19 O. Y. Henry, A. Fragoso, V. Beni, N. Laboria, J. L. A. Sánchez, D. Latta, F. Von Germar, K. Drese, I. Katakis and C. K. O'Sullivan, Electrophoresis, 2009, 30, 3398.

20 Y. Chen, H. Cui, J. Ye, S. Chong, T. Lim, F. Sheu and W. Hui, J. Phys.: Conf. Ser., 2006, 34, 198.

21 Z. Han, W. Li, Y. Huang and B. Zheng, Anal. Chem., 2009, 81, 5840.

22 M. Odijk, A. Baumann, W. Olthuis, A. van den Berg and

U. Karst, Biosens. Bioelectron., 2010, 26, 1521.

23 D. Quinton, A. Girard, L. T. Thi Kim, V. Raimbault, L. Griscom, F. Razan, S. Griveau and F. Bedioui, Lab Chip, 2011, 11, 1342.

24 P. Skafte-Pedersen, M. Hemmingsen, D. Sabourin, F. S. Blaga, H. Bruus and M. Dufva, Biomed. Microdevices, 2012, 14, 385.

25 L. Sasso, A. Heiskanen, F. Diazzi, M. Dimaki, J. CastilloLeón, M. Vergani, E. Landini, R. Raiteri, G. Ferrari, M. Carminati, M. Sampietro, W. E. Svendsen and J. Emnéus, Analyst, 2013, 138, 3651.

26 M. Dimaki, M. Vergani, A. Heiskanen, D. Kwasny, L. Sasso, M. Carminati, J. a. Gerrard, J. Emneus and W. E. Svendsen, Sensors, 2014, 14, 9505.

27 M. Vergani, M. Carminati, G. Ferrari, E. Landini, C. Caviglia, A. Heiskanen, C. Comminges, K. Zór, D. Sabourin, M. Dufva, M. Dimaki, R. Raiteri, U. Wollenberger, J. Emnéus and M. Sampietro, IEEE Trans. Biomed. Circuits Syst., 2012, 6, 498.

28 N. Kostesha, A. Heiskanen, C. Spégel, B. Hahn-Hägerdal, M.-F. Gorwa-Grauslund and J. Emnéus, Bioelectrochemistry, 2009, 76, 180.

29 K. Zór, M. Vergani, A. Heiskanen, E. Landini, M. Carminati, V. Coman, I. Vedarethinam, M. Skolimowski, A. M. Serrano, M. Kokaia, T. R. Moreno, A. Ghio, W. E. Svendsen, M. Dimaki, M. Adamovski, U. Wollenberger, D. Sabourin, G. Ferrari, R. Raiteri, M. Sampietro, M. Dufva, and J. Emnéus, Proc. $\mu$ TAS 2011, Seattle, 2011, 1532.

30 A. Heiskanen, V. Coman, N. Kostesha, D. Sabourin, N. Haslett, K. Baronian, L. Gorton, M. Dufva and J. Emnéus, Anal. Bioanal. Chem., 2013, 405, 3847.

31 D. J. Leszczyszyn, J. A. Jankowski, H. Viveross, E. J. Diliberto, J. A. Nears and R. M. Wightman, J. Biol. Chem., 1990, 265, 14736.

32 K. L. Adams, M. Puchades and A. G. Ewing, Annu. Rev. Anal. Chem., 2008, 1, 329.

33 C. Spegel, A. Heiskanen, L. H. D. Skjolding and J. Emnéus, Electroanalysis, 2008, 20, 680.

34 F. Lemaître, M. Guille Collignon and C. Amatore, Electrochim. Acta, 2014, 140, 457.

35 H.-F. Cui, J.-S. Ye, Y. Chen, S.-C. Chong and F.-S. Sheu, Anal. Chem., 2006, 78, 6347.

36 L. Amato, A. Heiskanen, C. Caviglia, F. Shah, K. Zór, M. Skolimowski, M. Madou, L. Gammelgaard, R. Hansen, E. G. Seiz, M. Ramos, T. R. Moreno, A. Martínez-Serrano, S. S. Keller and J. Emnéus, Adv. Funct. Mater., 2014, DOI: 10.1002/adfm.201400812.

37 A. Heiskanen, C. Spégel, J. Tønnesen, Z. Fohlerova, L. Goulart, J. Hansen, M. Kokaia, T. Ruzgas, M. Dufva and J. Emnéus, Proc. $\mu$ TAS 2008, San Diego, 2008, 1168. 
38 M. B. Taskin, L. Sasso, M. Dimaki, W. E. Svendsen and J. Castillo-Leon, ACS Appl. Mater. Interfaces, 2013, 5, 3323.

39 K. B. Anderson, S. T. Halpin, A. S. Johnson, R. S. Martin and D. M. Spence, Analyst, 2013, 138, 137.

40 I. A. Ges, R. L. Brindley, K. P. M. Currie and F. J. Baudenbacher, Lab Chip, 2013, 13, 4663.

41 S. T. Larsen and R. Taboryski, Analyst, 2012, 137, 5057.

42 M. W. Li, D. M. Spence and R. S. Martin, Electroanalysis, 2005, 17, 1171.

43 Y. Chen, C. Guo, L. Lim, S. Cheong, Q. Zhang, K. Tang and J. Reboud, Anal. Chem., 2008, 80, 1133.

44 A. R. Heiskanen, C. F. Spégel, N. Kostesha, T. Ruzgas and J. Emnéus, Langmuir, 2008, 9066.

45 L. M. Fischer, M. Tenje, A. R. Heiskanen, N. Masuda, J. Castillo, A. Bentien, J. Émneus, M. H. Jakobsen and A. Boisen, Microelectron. Eng., 2009, 86, 1282.

46 J. E. B. Randles, Discuss. Faraday Soc., 1947, 1, 11.
47 G. J. Brug, A. L. G. Van den Eeden, M. Sluyters-Rehbach and J. H. Sluyters, J. Electroanal. Chem., 1984, 176, 275.

48 K. Solly, X. Wang, X. Xu, B. Strulovici and W. Zheng, Assay Drug Dev. Technol., 2004, 2, 363.

49 A. Heiskanen and J. Emnéus, Applications of Electrochemistry and Nanotechnology in Biology and Medicine I, Springer New York, New York, NY, 2011, vol. 52.

50 G. Kretzmer and K. Schügerl, Appl. Microbiol. Biotechnol., 1991, 34, 613.

51 A. Ludwig, G. Kretzmer and K. Schügerl, Enzyme Microb. Technol., 1992, 14, 209.

52 T. K. Chen, G. Luo and A. G. Ewing, Anal. Chem., 1994, 66, 3031.

53 A. Heiskanen, J. Yakovleva, C. Spégel, R. Taboryski, M. Koudelka-Hep, J. Emnéus and T. Ruzgas, Electrochem. Commun., 2004, 6, 219. 